\title{
El derecho a la información electrónica
}

\author{
José María Desantes Guanter \\ Facultad de Ciencias de la Información \\ Universidad Complutense de Madrid
}

\subsection{Resumen}

Se analizan en el artículo las consecuencias que la aparición del documento electrónico trae consigo para la legislación en general y española en partícular. Para ello, tras analizar la situación en la que nos hallamos actualmente, pasa a desglosar las consecuencias que tiene para los componentes de la nueva cadena de la información (Sujeto, medio y mensaje). Además pasa revista brevemente a los diversos delitos que existen y como son castigados por el actual código penal.

Palabras clave: Documentos electronicos. Legislacion. Derecho a la información electrónica.

\subsection{Abstract}

The legal consecuences of electronic documents are analyzed. The current situation is considered. Therefore, the consequences for each component of the documentary chain -subject, media and message- are studied. finally, the different infingements related to electronic documents are reviewed, including punishment foreseen in current Spanish Legislation.

Keywords: Electronic documents. Legislation. Rights to electronic information.

\section{Técnica y Derecho}

Desde el punto de vista de la efectividad del derecho a la información a través del ciberespacio, es conveniente trazar dos líneas ordenadas que, al cruzarse, permitan situar los diversos problemas que se plantean y que seguirán planteándose/ de modo creciente, en el avance de la red mundial de información en general y, en concreto, al permitir la documentación electrónica.

a) La primera, a la que he dedicado un extenso libro, al cual me remito, es que el derecho a la documentación no es más que un caso concreto del 
derecho a la información, dado que la documentación no es más que una forma específica de comunicación puesta en forma modalmente. Y no una forma vicaria, sino trascendental puesto que la información conservada en el documento es, potencialmente al menos, vivificadora de nueva información. El tema es importante porque a todo lo que se diga de la documentación y, en concreto, de la documentación computerizada es aplicable el conjunto de principios que informan el Derecho de la Información, muy eminentemente el derecho mismo a la información como derecho humano o derecho natural.

b) La segunda es la afirmación de que técnica y Derecho, este último en el doble sentido objetivo y subjetivo, lejos de oponerse, tienen una tendencia a converger, frenada únicamente porque el Derecho objetivo o positivo tiene una evolución mucho más lenta que la técnica. No así el derecho subjetivo natural que no depende sino que informa al derecho positivo y, como más flexible por más directamente conectado con los principios, puede agilizar su aplicación al ritmo de los adelantos técnicos.

En efecto, como también he sostenido en otro lugar, la técnica no hace sino, por aplicación de la ciencia, descubrir las claves para dominar el mundo por el hombre, lo que indica que el mandato bíblico está acorde con la naturaleza humana.Estas claves, como el mundo mismo, nos debe llevar al descubrimiento del orden originario en que el mundo fue creado y que ya vieron claramente los griegos al designar el mundo y el orden con una sola palabra: cosmos. El caos o desorden en que aparentemente se mueve el mundo no es connatural a su creación, sino al mal uso que hacemos los hombres de los elementos que constituyen lo creado. La técnica va desenmarañando este caos o desorden y, como medio, va aproximando al hombre al dominio del mundo como fin. Se ha dicho que la informática, en concreto, es "una vuelta de tuerca" en el control de la naturaleza.

Pero la técnica no siempre está bien utilizada porque los hombres somos capaces de separar los medios de los fines a los que deben dirigirse; es decir, de hacer de la técnica algo que no ponga en manos del hombre el dominio del mundo, sino la autodestrucción total o parcial de sus posibilidades de realización. En este segundo caso, no se puede hablar de progreso técnico, sino de lo contrario: de regreso, por la perversa utilización de la técnica.

Todo lo que el hombre necesita para alcanzar sus fines, que es a lo que he llamado realización, forma parte natural de su personalidad que está protegida por los derechos subjetivos, entre ellos el derecho genérico a la información y su especie, el derecho a la documentación. En tanto la técnica satisfaga de mane-

Scire. 3 : 1 (ene. -jun. 1997) 55-73 
ra creciente estos derechos, es verdadera técnica. En tanto los contradiga, estamos ante una inversión mediática de la técnica. Habermas ha dicho que "al desafío de la técnica no se puede responder solamente con la técnica". Efectivamente, es necesario el derecho subjetivo natural como principio, que es anterior y superior a la técnica; y el Derecho positivo o Derecho como norma imperativa que, desgraciadamente, se promulga con un enorme retraso, y no siempre con acierto, con respecto a los avances de la ciencia y de su aplicación técnica, lo que produce distorsiones en la vida social.

En consecuencia, es necesario tener en cuenta los elementos del progreso técnico, en este caso del ciberespacial, para, comparándolos con el derecho natural a la información, calibrar su verdadero sentido y corregir las desviaciones en su utilización. Por otra parte, hay que conocer la realidad de la técnica, progresiva o propiamente dicha, como la informática, para llevar a cabo una ajustada positivación del Derecho regulador y una buena aplicación de sus normas.

\section{Insuficiencia de una "Ética ciberespacial"}

"EL ciberespacio es un microcosmos digital en el que no existen fronteras, distancia, ni autoridad centralizada", según define Pérez-Luño. La participación en él es necesaria para sentirse miembro de la sociedad mundial. Pero la problemática que presenta en orden al derecho a la información dificulta una regulación concreta por su internacionalidad y por la mutación constante de sus procedimientos, cuyas variaciones pueden ser valorativamente ambivalentes: representar un avance o un retroceso tecnológico. Y, en el primer caso, ser utilizadas recta o torticeramente.

Se ha propuesto, como solución, el establecimiento de un nuevo sistema de "Ética ciberespacial", lo que resulta aceptable como enunciado teórico. Pero, para que pueda tener una proyección práctica, hay que partir de la característica de sus normas, que puede esquematizarse así:

1. Que su formulación no es más que la aplicación concreta de los superiores principios éticos aceptados ulniversalmente porque son connaturales a la naturaleza humana.

2. Que las determinaciones de estos principios requieren normas sucesivamente positivizadas de carácter convencional o consuetudinario, dados sus planteamientos y efectos a nivel supranacional.

3. Que, dada la rapidez con que se producen las nuevas técnicas en relación a las normas, no sólo legales, sino tambien convencionales y consuetudinarias, siempre habrá una etapa de vacío normativo positivo que solamente podrá llenarse con una especificación de principios de justicia.

Scire. $3: 1$ (ene. -jun. 1997) 55-73 
4. Que la rapidez con que se pueden crear y difundir los documentos en la información electrónica tiene como consecuencia la dificultad en la detección de las infracciones a efectos de atribuir responsabilidades. Y, atribuidas a estas, la imposibilidad de tipificar totalmente las posibles desviaciones que el poder de la técnica permite, lo que puede hacer inútil todo esfuerzo de normalización efectiva de la actividad ciberespacial.

No obstante, hay normas positivas vigentes en los ámbitos nacionales y en los supranacionales acerca de aspectos muy concretos de la fenomenología ciberespacial. Estas son normas que, en tanto no son sancionadoras, admiten una aplicación analógica a nuevas realidad

Si bien ha de ser delicada su práctica para no exceder aquello que no sea coincidente entre el supuesto fáctico de la norma vigente y el nuevo supuesto huérfano de una regulación idónea. El fracaso de la aplicación de las normas reguladoras del telégrafo a la radiodifusión fue patente y, sin embargo, retrasó el que se formarán los medios radioeléctricos.

En definitiva, la nueva ética ciberespacial traducida a términos jurídicos, habría que conducirla a través de tres vías:

1. Una primera negativa: el respeto a las libertades y los bienes amenazados por una utilización inadecuada del ciberespacio

2. Una vía solidaria: el establecimiento de vínculos entre entidades de todo tipo para prevenir las irregularidades electrónicas y la ayuda mutua para descubrirlas.

3. Una vía positiva: la promoción real y eficaz del derecho a la información en sus tres facultades: investigación, recepción y difusión de mensajes propiamente tales, a través de unos medios de comunicación técnicamente adecuados.

En todo caso, tanto los principios no positivizados, cuanto las normas positivas de cualquier especie de que se trate, han de tener en cuenta las realidades ciberespaciales o electrónicas. De otro modo, la regulación y su aplicación en cada caso no sería ajustada y, por tanto, resultaría ineficaz en términos jurídicos. Ésta es una de las ventajas que se esgrimen para no tener prisa en promulgar una normación concreta hasta que sean muy bien conocidos los fenómenos reales que es necesario regular. Una regulación precipitada, aparte de su precariedad cronológica, puede traer distorsiones contrarias a la realidad que la norma se propone encauzar a un fin; o crear falsos derechos adquiridos muy difíciles de desarraigar. 
El conocimiento de la realidad informática ha de ir acompañado de un análisis de los elementos que constituyen el proceso informativo ciberespacial para conjugarlos con el que podemos llamar "superprincipio del derecho a la información", cuyas características y contenido hemos de dar aquí por sabido. La configuración permite un tratamiento de principios o de normas tal que se cumplan efectivamente el derecho comunicativo necesario para la realización del hombre y de la comunidad.

\section{La realidad}

Si nos referimos, como ejemplo, al fenómeno de Internet no resulta acertado aplicar analógicamente normas positivas anteriores. En el caso relativamente más aproximado de la telemática, la información estaba centralizada en uno o varios servidores a los que les resultaba posible supervisar las fuentes de información y eran, a la vez, susceptibles de ser controlados. En el Internet, por axioma, no hay centralización posible de mensajes, ni de documentos, puesto que es una red mundial que conecta a un número teóricamente ilimitado de ordenadores esparcidos por todo el planeta con otro número ilimitado de ordenadores dispuestos a recibir información. Lo que facilita el acceso a documentos o ficheros que, en poco tiempo, habrá que contar por billones y que contienen una cantidad y calidad de información inasequible a una delimitación y clasificación valorativas. Y no se puede perder de vista que el desarrollo tecnológico digital avanza en progresiones geométricas.

Los procedimientos para "navegar" por Internet, como la -World Wide Web (WWW) o tela de araña mundial - son sistemas técnicos que permiten la investigación y consiguiente recepción de lo que, en uso de la facultad de difusión, alguien -conocido o no- ha situado en un soporte informático. Esta realidad técnica produce como efectos otras realidades sociales, unas favorables y otras adversas. El papel del Derecho está en evitar las segundas y potenciar las primeras en aras de los derechos subjetivos, naturales, estatutarios o concertados.

La información creada de nuevo o contenida en un documento anterior se transforma en un flujo de electrones que fluyen en una cantidad y a una velocidad hasta hace poco increibles. La posibilidad de almacenar esta riqueza de mensajes y de poder disponer de ellos momentáneamente en una pantalla, de la que pueden obtenerse simultáneamente impresiones, sin limitación posible $-\mathrm{y}$ por otra parte, no deseable- de fronteras lleva a hacer real una integración mundial que ya fue prevista por nuestros clásicos con motivo del descubrimiento de un Nuevo Mundo.

Antes que nadie Francisco de Vitoria, en el Siglo XVI, hablaba del Totus Orbis y de la Quasi republica universale, que era fruto del ius communicationis,

Scire. 3 : 1 (ene. -jun. 1997) 55-73 
un solo derecho con el ius societatis, empalmando con la idea griega de la koinonia, que significaba igualmente comunicación y comunidad. La posibilidad actual de una comunicación instantánea y, al menos potencialmente, total inicia un proceso imparable de verificación de la comunidad que ya no se llamará internacional, ni superestatal, sino universal. Obsérvese la advertencia que supuso el que la Declaración de Derechos Humanos de la Organización de las Naciones Unidas de 10 de diciembre de 1948 se apellidase ya como Universal. Y que en ella destacase el derecho a la información y los derechos afines, como el derecho de autor, como concreción, o el derecho a la no discriminación como generalización. Y téngase en cuenta, como han afirmado Organizaciones supranacionales, como la Comunidad Europea que, aun no siendo el derecho a comunicarse el primario, es el más urgente porque es el que permite la salvaguarda de todos los demás.

Ahora bien, en el caso de Internet el " vacío legal “ es más bien un vacío de regulación universal que, sin embargo, se ve como necesaria. Esta misma universalidad potencial, cuyas mutaciones sociales se irán produciendo desigualmente según las posibilidades y la idiosincrasia de los pueblos, presenta también inconvenientes actuales.

La participación en el ciberespacio exige unos medios caros que suponen una infraestructura tecnológica que no todos los paises y las empresas de producción pueden sostener, lo que, sin duda, producirá una mayor desigualdad entre personas y grupos. No hay que olvidar que el que tiene la información tiene el poder político y económico y al que tiene el poder le está permitida una optimización de los recursos, propios y ajenos, en un mundo ya complejo y desigual que pone en peligro el principio de no discriminación y el de igualdad de oportunidades.

En otro aspecto, hay que añadir las dificultades generales derivadas de la utilización de las "infopistas". Aún cuando exista un ancho de banda para soportar un tráfico enorme, es más rápido el crecimiento que desborda la capacidad de las redes y el tiempo de los usuarios. Ya en este momento, cuando el desarrollo es ínfimo en relación al que se prevé en un próximo futuro, en las horas punta, los retrasos en la consecución de conexiones y los bloqueos dificultan o impiden una utilización fluida y oportuna.

Dificultades que crecen con el gran número de tipos de ordenadores, programas y formas de organizar la documentación. A lo que hay que añadir la frecuente mutabilidad de los recursos y de las direcciones, que impiden su localización.

Finalmente, el que no sea fácil localizar responsabilidades visibles, ni controlar el establecimiento de planes, programas y contenidos lleva al recelo de los

Scire. $3: 1$ (ene. -jun. 1997) 55-73 
poderes públicos, especialmente los que más competencias están perdiendo: los de carácter estatal. Se duda entre el establecimiento de una regulación estricta que hace presuponer una ideología intervencionista, poco efectiva a la larga y que puede ser desbordada por otros regímenes más abiertos, y una posición liberal en el establecimiento o no establecimiento de normas, o de desregulación de las anteriormente establecidas, que puede llevar a una situación de anarquía por parte de todos.

Resulta imposible atender al remedio de estos inconvenientes en un solo cuerpo normativo cuando, además, la realidad desborda a toda norma y una disposición general puede ir quedando cuarteada por la aparición de nueva tecnología y, por tanto, sin las ventajas sistemáticas que tiene la codificación. Pero es necesario que las normas legales, convencionales o consuetudinarias, por fragmentarias que sean, no olviden que el ordenamiento genera el orden, lo que exige que todas ellas se dirijan hacia un mismo norte que es hacer efectivo el derecho a la información. Esta dirección es la que permitirá una crítica favorable de la norma; y su separación de ella, una crítica desfavorable porque será desintegradora del sistema y desordenadora. La generalidad de esta meta última, exige un análisis de los términos del proceso jurídico informativo: sujetos diversos, medios y mensajes.

\section{El sujeto universal}

El ciberespacio ha disipado las dudas acerca de la operatividad efectiva de las tres facultades que integran el derecho a la información. Se veía que era posible y aun corriente, aunque no sin problemas, la posibilidad de ejercitar la facultad de recepción, incluso gratuitamente en el caso de los medios audiovisuales. Pero no sólo se dudaba, sino que en ocasiones se negaba la posibilidad de ejercitar las facultades de investigación y de difusión por cualquiera. Como la realidad se impone, podían presentarse ejemplos de que, poco a poco, se iban abriendo cauces para transitar por ellos. Pero eran álveos concretos en cuanto a la facultad a utilizar y el modo cómo se utilizaban. El modo electrónico abre un cauce de holgura suficiente para que en él entren las tres facultades que pueden ejercitarse por todos, con todos los objetos posibles y con simultaneidad.

Esta omnímoda posibilidad opera principalmente en favor del sujeto universal o sujeto no profesional, ni organizado: toda persona física y, por extensión, toda persona jurídica. Pero no deja de ser una potencialidad operativa que puede resultar trabada por inconvenientes fácticos o materiales. El primero es el coste, tanto de los artilugios a utilizar cuanto de los servicios en el supuesto de que estén sometidos a un canon. Afortunadamente, el precio de los aparatos electrónicos, que no siempre ha coincidido con su coste, se va reduciendo a buen ritmo, lo mismo que su tamaño. No así el pago de los servicios donde existen situacio-

Scire. $3: 1$ (ene. -jun. 1997) 55-73 
nes monopolísticas u oligopolísticas que impiden la libre competencia con lo que es aspiración de los usuarios, que el establecimiento y utilización de los servicios ciberespaciales no sea objeto de especulación económica para que exista una verdadera teledemocracia.

Estrechamente ligado a este problema queda, por activa y por pasiva, la resolución de las cuestiones que afectan a las facultades económicas del derecho de autor, a las que no me voy a referir porque son objeto de otra intervención.

En todo caso, la que se ha llamado "sociedad de la información" permite teóricamente que toda persona física y jurídica pueda adoptar todas las actitudes informativas del sujeto universal que se han estudiado como posibles: elementales, activas, participativas, contestatarias y colaborantes. Digo teóricamente, al menos, porque esta posibilidad viene prácticamente reducida por la complejidad del manejo de los aparatos y métodos emisores y receptores de mensajes electrónicos, acrecida, entre otras razones, por las normas editadas por los fabricantes, forzadas por una deficiente traducción y porque han de buscar términos analógicos que permitan la digitalización rápida de los modos de actuar. Esto hace que, cuando se leen cifras de actuales usuarios sorprendan los números absolutos; pero que sorprenda también lo reducido de los números relativos resultantes al compararlos con la población del mundo. Lo que nos aleja de la utopía -que no es irreal utopismo- de la universalización.

El hecho empero, de que cada persona pueda crear y difundir mensajes extiende mucho el grupo de los responsables que pueden cometer infracciones, bien porque les falte el constitutivo esencial de la verdad para que puedan ser auténticos mensajes y no su apariencia; bien porque no se ha advertido que los derechos humanos no pueden desconcertarse. O, dicho de otro modo, que la libertad de información no tiene sentido por sí misma, sino que es el modo libre de hacer efectivo el derecho a la información con lo que el servicio imprescindible que presta a este derecho le confiere la naturalidad e inviolabilidad características del derecho mismo. Sin perjuicio de ver que las tipificaciones penales afectan también a los factores humanos del medio, se expondrá esquemáticamente el tema al tratar de los mensajes.

Una manifestación de la facultad universal de investigar y rectificar, en su caso, los datos que figuran en cualquier base o depósito informático, y que en Internet pueden difundirse en cualquier momento, es el que la doctrina y algunas constituciones/ como la de Perú o la de Colombia, conocen con el nombre de habeas data por su remota semejanza con otro cauce procesal más conocido que es es el habeas corpus. Nuestros autores lo conocen como "derecho a la autodeterminación informática", traduciendo literalmente la expresión alemana que lo nombra : informationelle Selbstbestimmung . La cuestión tiene suma

Scire. 3 : 1 (ene. -jun. 1997) 55-73 
importancia porque, aparte del derecho a que la información que afecta a un sujeto sea verdadera, el habeas data atenúa el peligro de que el cruce de ficheros convierta informaciones parciales y dispersas en informaciones organizadas que pueden, incluso, afectar a la intimídad de las personas.

En España contamos con la llamada LORTAD o Ley de Regulación del Tratamiento Automatizado de Datos de Carácter Personal, ley 5/1192 de 29 de octubre, como desarrollo del artículo 18, 4 de la Constitución. La LORTAD obedece a una serie de compromisos internacionales asumidos por el Estado español más en relación con el derecho sustantivo a la intimidad que con el cauce procesal del habeas data, no obstante su parcial referencia a él. La Ley se dictó tarde en relación con determinados escándalos que se produjeron con la utilización de diversos datos y tiene el defecto de muchas leyes españolas: reconocer un principio garantizador de un derecho y establecer tantos supuestos de excepción que dejen muy mermadas las garantías efectivas.

Más cerca de la idea del habeas data se sitúa la Sentencia del Tribunal Constitucional 254/1993 de 20 de julio que reconoce y ampara el derecho de los ciudadanos a conocer los datos personales que les conciernen y se hallan registrados en archivos administrativos informatizados. En sentido contrario a esta garantía del ciudadano, está la Sentencia del mismo Tribunal 143/1994 de 9 de mayo en la que, por razones no muy convincentes, se admitió la legalidad del Real Decreto 338/1990 regulador del NIF o Número de Identificación Fiscal.

Particular importancia adquieren también los problemas del sujeto cuanto éste es una persona jurídica, sea pública o privada, que en unos casos puede y en otros debe estar informatizada para hacer efectivo el derecho y el deber de informar, respectivamente. La Ley 30/1992 de 26 de noviembre de Régimen Jurídico de las Administraciones Públicas y del Procedimiento Administrativo Común declara en su Exposición de Motivos que "las Administraciones Públicas impulsarán el empleo y aplicación de las técnicas y medios electrónicos, informáticos y telemáticos, para el desarrollo de su actividad y el ejercicio de sus competencias, con las limitaciones que a la utilización de estos medios establecen la Constitución y las leyes". La Administración tiene también el derecho y el deber de utilizar la informática para establecer una transparencia administrativa que lleve consigo, como consecuencia, la adhesión del público.

La Administración de Justicia cuenta también con el derecho y el consecuente deber de informatización, aunque en nuestro caso afecte tan sólo al aspecto jurídico documental, sometido a las discreciones procesales; y no al metadocumental o decisional, dirigido este último a ofrecer soluciones al juez cuando los datos en juego son complejos y el número de normas positivas que pueden ser aplicables al caso controvertido es agobiante.

Scire. $3: 1$ (ene. -jun. 1997) 55-73 
Por su propia normativa, establecida por convenciones, hay que reconocer el mismo derecho y deber a las Organizaciones supranacionales; algunas de ellas pueden parecer muy secretas como la OTAN que participa en Internet del mismo modo que las Fuerzas Armadas de los Paises de la Organización, entre ellas España.

Finalmente, también corresponden a las Entidades privadas de todo tipo que, según su naturaleza y fines, tienen no sólo el derecho, sino el deber de informar de que sus actividades son congruentes con el propio fin lo que, con el antecedente de la relatio publica romana, constituye la naturaleza de las relaciones públicas.

\section{El sujeto profesional}

Las dificultades técnicas informáticas que encuentra el sujeto universal no tienen razón de existir para el profesional, tanto en la incorporación cuanto en el almacenamiento y recuperación de los mensajes. El sujeto profesional ha de estar cualificado porque, así como en cuanto ciudadano actúa en el ejercicio de su derecho a la información, en cuanto mediador en la información actúa por su deber de informar.

Aquí es necesaria, como en ningún otro aspecto la ética del ciberespacio concretada en forma de una deontología cualificada, ya que le es difícil al Derecho obligar o prohibir haceres privados concretos, limitándose a exigir y comprobar el deber de conocimiento suficiente de la técnica y el deber de diligencia en su aplicación. Las reglas técnicas, en cuanto favorecen el flujo de la información, se transforman en reglas éticas y, en último caso, en jurídicas.

Ahora bien, son muchos los tipos de profesionales que pueden intervenir en los multimedia -que deberían llamarse multimodos, si no se quiere confundir medio y mensaje- y muchas, pero especializadas, las reglas técnicas que permiten conjugar diferentes tipos de mensajes a través de los hiperenlaces. Hay que adaptar el principio troncal del deber diligente de informar a cada tipo de menester profesional.

Por otra parte, cualquier sistema de redes de ordenadores, como el Internet, viene a ampliar el campo de deberes de los profesionales dedicados a los medios tradicionales, puesto que no sólo permite disponer de mensajes antes inasequibles, sino también los elementos necesarios para su complitud -imagen o diseño para la información escrita, por ejemplo- y para el ahorro de tiempo y esfuerzo y su valoración en términos absolutos y relativos.

Esta nueva savia con que se vitaliza el deber troncal de informar, produce una riqueza de ramificaciones de deberes concretos y, en su caso, de obligaciones cuando se trata de profesiones relacionadas con la documentación. En efec-

Scire. 3 : 1 (ene. -jun. 1997) 55-73 
to: se amplía enormemente el concepto de archivo o depósito, hasta poder llegar a su universalización; en teoría, se pueden relacionar automáticamente todos los depósitos documentarlos; es ilimitada la capacidad de almacenamiento y de duración de la documentación digital, sin necesidad de ocuparse de su mantenimiento y conservación, se agiliza hasta el extremo el proceso de recuperación; el hipertexto permite la creación de nuevos documentos conjugando varios de los existentes de cualquier tipo de mensajes, lo que añade el deber de creación de mensajes y de generación documental, complicando así las normas de derecho de autor; deber generativo que se ha de ejercitar también cuando se convierten los bits en átomos para trasladar los mensajes en pantalla a los soportes corporales, sean conocidos, como el papel, o de otro tipo.

La informática permite también, en determinadas circunstancias, el teletrabajo del que se discuten vivamente las ventajas e inconvenientes. Pero, sea cualquiera el saldo resultante, siempre consiste en una posibilidad que se puede aprovechar cuando los beneficios recíprocos de deudor y acreedor de trabajo sean positivos. Lo que generará, por otra parte, modificaciones sustantivas y procesales en los contratos laborales informativos.

El deber de informar, que ha de concertarse con la libertad de decisión del profesional dentro de una disciplina técnica -aquí hay que invocar también la cláusula de conciencia- lleva consigo un haz proporcionado de responsabilidades. Las compensatorias, si no están determinadas, pueden siempre exigirse aplicando el principio general del artículo 1902 de Código civil; pero las penales han de estar tipificadas y a ellas, en el plano doctrinal y positivo, nos referiremos al tratar del medio y del mensaje.

\section{El sujeto organizado}

De estas responsabilidades participa también el sujeto organizado, especialmente la empresa, aun cuando sea en la persona de su representante, gestor o administrador; y ya sea de una manera directa o subsidiaria. Pero por la vía de la responsabilidad se puede deducir la cantidad de tipos de empresas que intervienen en el proceso informativo digital. Desde las empresas fabricantes de aparatos necesarios para operar, de un modo o de otro, en la informática, hasta las que utilizan las facilidades de la comunicación digital para producir medios de información nuevos o tradicionales que duplican las posibilidades informativas introduciéndose, a su vez, en las redes digitales.

La responsabilidad de la organización hinca su raiz en que también la organización participa del deber de informar, lo que exige igualmente la aplicación de la ética informática, de la que, por su energía poyética, se podrán obtener normas jurídicas, en su caso.

Scire. 3 : 1 (ene. -jun. 1997) 55-73 


\section{El medio}

Los autores, incluso juristas, hablan de informática, de ciberespacio, redes o autopistas de información, de digitalización del proceso informativo, etcétera. No se refieren al resultado de esos procesos que es un medio de comunicación, ni lo estudian en cuanto medio informativo. Sin embargo, como ha ocurrido con la documentación, su emplazamiento como verdadero medio de comunicación que es, permite verter en él todos los principios generales de los media y, por un proceso de deducción, ir enriqueciendo la doctrina documentarla y, en concreto, el derecho subjetivo a la documentación y el Derecho objetivo de la Documentación. Es el método jurídico conocido como "jurisprudencia de principios" cuya aplicación resulta fecunda.

Por otra parte, la ampliación de la base empírica que se produce por tal consideración como medio, genera, por inducción, un proporcionado enriquecimiento de la teoría general de los medios. La llamada "revolución de la información" lleva consigo, como consecuencia, una "evolución del Derecho" muy anterior a la innovación de las normas positivas.

En cualquier caso, y en el momento actual, el ciberespacio produce lo que se ha llamado multimedia, fenómeno nuevo en cierta manera porque, desde hace tiempo, se había producido ya en pequeña escala con los conocidos medios simbióticos en los que la combinación, en diferentes dosis y funciones, de medios tradicionales, dan lugar a efectos nuevos que aumentan la realización eficaz del derecho natural a la información, entendiendo por información todo tipo de mensajes y no sólo los que difunden noticias. Piénsese, por ejemplo, en la simbiosis entre cine y televisión.

El proceso puramente simbiótico o, en ocasiones, parásito de un medio con respecto a otro se ha visto sobresaltado por el acoplamiento de información y telecomunicación lo que ha dado lugar no sólo a nuevas formas de simbiosis, sino además a los llamados multimedia en los que son posibles las conjunciones de varios medios y su recíproca potenciación. Cuando esta vigorización exponencial llega al máximo, podemos afirmar que no existe una conexión de los media, sino el media por excelencia. Es decir la posibilidad de actuar conjunta y unitariamente las posibilidades comunicativas de varios medios que, potenciándose mutuamente, generan un nuevo medio.

Si por medio se conoce la inserción de un mensaje en un soporte, entendido este en un sentido amplísimo o universal, no se puede negar la calificación de medio, todo lo nuevo y peculiar que se quiera, al fecundo resultado incorporativo del ciberespacio.

No es cuestión de exponer aquí la aplicación de los principios generales que rigen los medios a los procesos de integración que dan lugar al multimedia,

Scire. 3 : 1 (ene. -jun. 1997) 55-73 
como el de globalidad, libertad, unidad, responsabilidad conjunta en el resultado, etcetera. Podemos, empero, apreciarlo en un tema tan importante como el que resulta de la responsabilidad penal.

De modo paralelo a lo que ocurre en los delitos informativos, hay que distinguir en el mundo de la electrónica delitos informáticos o que afectan al funcionamiento de los sistemas digitales; y delitos que se cometen a través de la informática utilizada como instrumento para lesionar bienes jurídicos u ocasionar peligros personales o sociales. El lugar de estos últimos es la exposición del mensaje. Al tratar del medio hay que ocuparse de los primeros. Bien entendido, que en el lenguaje corriente y en el de los técnicos se entiende por delito informático cualquier infracción sea delito o falta, sea penal, civil o administrativa, de lege data o de lege ferenda, cuando todavía no es más que una aspiración el que se tipifiquen penalmente.

El delito informático estrictamente hablando, dejando aparte el que se comete a través de la informática, se identifica con las lesiones ilícitas del patrimonio conformado por los ordenadores, ya sea en su equipo físico o en sus programas y sistemas. Es decir, tiene un elemento objetivo que solamente conocen losespecialistas informáticos o insiders, personas empleadas o que han sido empleadas en organizaciones informativas, lo que facilita el que se detecten frecuentemente infracciones perpetradas por especialistas en venganza de personas o de empresas. Lo conocen también los llamados hackers o intrusos capaces de acceder a los sistemas informáticos indebidamente, merced a sus conocimientos de las nuevas tecnologías, que frecuentan las redes con afán lúdico, económico o dolosamente delictivo.

En términos generales, puede decirse que son infracciones que atentan contra la fase de entrada o de salida del sistema, contra su programación, elaboración, procesamiento de datos y comunicación telemática. A título no exhaustivo, por las fluctuaciónes e innovaciones tecnológicas incesantemente cambiantes, se puede citar algunos, conocidos, a voces, con nombres pintorescos resultantes de las traducciones de otros idiomas, principalmente del inglés:

- Uno de ellos está constituido por la llamada "bomba lógica" o introducción en un programa de un conjunto de instrucciones indebidas que, en determinadas circunstancias, dañan o destruyen los datos del ordenador, distorsionan el funcionamiento del sistema o, incluso, provocan su paralización intermitente o indefinida.

- Otro son los virus informáticos o programas que poseen una secuencia reproducible en la memoria del ordenador y contaminan a otros sistemas por los dispositivos de transferencia o por las conexiones con las redes. 
- Más en general, el sabotaje informático que tiende a inutilizar los sistemas informáticos dañando la programación o los sistemas operativos.

- Los llamados caballos aparentemente útiles o de Troya: introducción de instruccionesinocuas que distorsionan el funcionamientodel sistema informático para que el ordenador lleve a cabooperaciones no autorizadas,.como transferencia de fondos a la cuenta del delincuente

- La fuga de datos o robo y hurto de software versión sofisticada del espionaje industrial y comercial' cuando los datos de organizaciones públicas o privadas se hallan archivadas en soportes informáticos.

- El parasitismo informático o conducta que tiene por objeto el acceso ilícito a los programas informativos para utilizarlos en beneficio del parásito.

- Las llamadas puertas falsas o aprovechamiento de accesos de entrada al programa que no está previstos en las instrucciones de aplicación, pero que existen.

- Las llaves maestras que permiten abrir cualquier archivo del ordenador aunque esté protegido por medidas de seguridad.

- El pinchado de líneas o interferencias telefónicas o telemáticas por las que se transmiten informaciones procesadas en las bases de datos.

- La apropiación de informaciones residuales o sustracción de datos que han sido abandonados por los legítimos usuarios de servicios informáticos como resíduo de determinadas operaciones.

- La llamada técnica del salami, difícil de detectar, consistente en redondear pequeñas cantidades de activos de numerosas cuentas bancarias para desviar una cantidad notable por la suma de todas ellas en la cuenta del delincuente.

La delictividad informática comporta grandes dificultades en su persecución, descubrimiento y prueba, lo que debería entrañar una penalidad agravada. En ocasiones queda falta de tipificación en los códigos penales desde el momento mismo de su promulgación, como ocurre con el Código Penal vigente aprobado por Ley Orgánica 10/95 de 23 de noviembre. Aparte de introducir la protección penal de la intimidad y del derecho de autor, la primera tipificación de delitos informáticos en un Código Penal español puede esquematizarse así:

- La utilización ilícita o abusiva de tarjetas magnéticas como modalidad de utilización de llaves falsas (art. 239).

- La transferencia no consentida de cualquier activo patrimonial en perjuicio de tercero a través de un manipulación informática o artificio semejante, con ánimo de lucro como variedad de la estafa (art.248,2). 
- Las defraudaciones que tienen por objeto las telecomunicaciones (art.255); y el uso de cualquier equipo terminal de telecomunicación sin consentimiento de su titular, ocasionando a éste un perjuicio superior a 50.000 pesetas como delito (art. 256) o inferior a esta cantidad como falta (art. 623,4).

- La destrucción, alteración, inutilización o daños generales ocasionados a datos, programas o documentos electrónicos ajenos contenidos en redes, soportes o sistemas informáticos art. 264,2).

- La fabricación, puesta en circulación y tenencia de cualquier medio específicamente destinado a facilitar la supresión no autorizada o la neutralización de cualquier dispositivo técnico que se haya utilizado para proteger programas de ordenador (art.270).

- El apoderamiento, por cualquier medio, de datos, documentos escritos o electrónicos o soportes informáticos (art. 278,1); o el apoderamiento o destrucción de los mismos soportes informáticos (art. 278,3).

\section{El mensaje}

El elemento estabilizador del sistema jurídico informativo, incluidos los medios informáticos, está constituido por el derecho al mensaje, el elemento menos regulado positivamente y el más estudiado doctrinalmente con arreglo a la "jurisprudencia de principios". A diferencia del sujeto y del medio, el mensaje no se rige por el principio de universalidad, sino por el de generalidad. En otras palabras, no todo lo que se puede difundir sedebe difundir. En un sentido riguroso solamente merece el nombre de mensaje aquello que es jurídicamente difundible o difundendo. Lo demás son contramensajes porque en lugar de informar desinforman.

El elemento estabilizador no consiste en agarrotar los mensajes propiamente dichos, sino en mantener su regulación sea cual quiera el medio por el que se difundan y el desarrollo del mismo. La gran variedad de mensajes posibles se ha logrado analizar y clasificar, al menos en cuanto a los mensajes simples y a los más frecuentes de los complejos. Todos ellos regidos por el principio de generalidad. El único supuesto en que el principio se flexibiliza es en el mensaje documentario, no como mensaje documental o documento que se difunde sobre el que sigue gravitando el principio de generalidad, sino sobre los mensajes documentados o integrados en documentos que se han conservado previamente, lo que comprueba que es la variedad del modo documentarlo la que hace que los mismos principios jurídicos tengan soluciones aparentemente dispares, pero que sustantivamente son homogéneas.

Scire. 3 : 1 (ene. -jun. 1997) 55-73 
Los mensajes obtenidos a través del ciberespacio no tienen distinta regulación, en cuanto tales mensajes, que los incorporados a soportes tradicionales o documentales, en su caso. Otra cosa es que la ampliación de las posibilidades y la rapidez de obtención hagan, por una parte, más eficaz el derecho a la información; o, por el contrario, más peligrosa su violación: es conocida la regla de que lo mejor, al corromperse, produce lo peor. Tal corrupción procede de dos fuentes posibles: desvirtuar el mensaje sustrayéndole su elemento constitutivo; o ignorar que el derecho a la información se realiza al ritmo de la efectividad de los demás derechos naturales y que no puede haber entre ellos contraposición, ni pueden, jurídicamente hablando, limitarse unos a otros como generalmente se afirma.

El constitutivo esencial de todo mensaje es la verdad. Los tipos más simples de mensajes de cuya combinación resultan los demás surgen de las tres especies de verdad: la verdad lógica o adecuación de realidad e intelecto, que preside el mensaje de hechos o noticia; la verdad operativa o bien, que dirige mensaje ideológico; y la verdad criteriológica que conduce mensaje de opinión. Estos tres tipos de información pueden suministrados por los sistemas electrónicos, así como diversas combinaciones que dan lugar a los mensajes complejos serán tales y no apariencia de mensajes si están constituidos por sus respectivos tipos de verdad.

El Derecho referente a los mensajes que circulan por vía electrónica se ha fijado especialmente en los mensajes fácticos y ha estudiado los delitos que se cometen a través de los multimedia a base de ponderarles con la medida de la verdad lógica. Por eso condena los fraudes a través de manipulaciones que tienen por objeto interferir o distorsionar los datos procesados en sistemas informáticos. O los datos engañosos contenidos en el ordenador antes o durante su proceso informático, tanto incluyendo informaciones falsas, cuanto eliminando aquellas que son verdaderas.

A la zaga del Derecho, la legislación va acogiendo algún delito que proteja la verdad lógica en los mensajes obtenidos mediante los sistemas ciberespaciales. El nuevo Código Penal de 1995, ya citado, tipifica como conducta criminal la fabricación o tenencia de programas de ordenador específicamente destinados a la comisión de delitos de falsedades (Art. 400).

Así como la definición de verdad lógica nos indica que la certeza se funda en la realidad, en la verdad operativa y, por tanto, en la comunicación ideológica no hay sujeción posible, dado que cada cual puede considerar diferentes cosas como bienes. Lo que no puede considerarse como bien es el mal por naturaleza, lo que los romanos llamaban mala quia mala, ni menos presentar estos males como bienes. El bien es lo que todos apetecen, con lo que su falsa apariencia sin

Scire. 3 : 1 (ene. -jun. 1997) 55-73 
fundamento sería inducir al mal. Y mal absoluto es la violencia que, en pensamiento de Aristóteles, es lo que repugna a la naturaleza y que tiene diferentes expresiones: la guerra y el terrorismo como hasta el presente las más graves. Otro mal absoluto es la pornografía o aquel tipo de erotismo obsceno que va contra la dignidad de las personas. Una y otra deficiencia del bien o verdad operativa se ha frecuentado en el ciberespacio sin que se hayan encontrado medios jurídicos adecuados para evitarla y, en su caso, sancionarla.

Lo mismo ocurre con la información opinática que, aunque marca la mayor apertura posible del compás del libre ejercicio del derecho a la información, tiene sus reglas criteriológicas que no es posible analizar aquí; muchas de ellas de sentido común y que irracionalmente no se respetan.

En otro aspecto, el derecho a la información ha de concertarse con los demás derechos humanos para la realización armónica y fecunda de todos ellos. No se puede decir que el derecho a la información, bien entendido, se opone al derecho a la vida, a la libertad, a la dignidad, a la intimidad, a la propia imagen y a la paz, ni viceversa. No se puede decir que esos derechos limitan al derecho a la información; porque las lesiones por las técnicas difusivas de cualquiera de esos derechos, van contra el mismo derecho a La información. No es posible difundir, investigar o recibir información sin vida o sin libertad. El desprecio a la dignidad produce desconfianza que se opone a la comunicación. La intromisión en la intimidad frena la fuente de producción de informaciones ideológicas o valorativas por el hombre. La defraudación de la imagen destruye a la larga la comunicación iconográfica. Ir contra la paz es la violencia con todas sus secuelas, entre ellas la guerra, que produce incomunicación entre las partes beligerantes.

La posibilidad de cortar todos estos tipos de desinformación es difícil. La vida y la libertad tienen una protección penal como tales, pero no suficiente en relación con la información. Existe el delito de apología del delito; pero los jueces encuentran problemas cuando se trata de la apología de determinados crímenes, entre ellos el terrorismo.

Honor, intimidad y propia imagen cuentan con una deficiente Ley Orgánica, la 1/1982 de 5 de mayo de protección civil. La dignidad, concepto más estricto que el honor, cuenta con una larga historia de protección penal a través de la injuria, la calumnia y la difamación, esta última encubierta en nuestro Codigo Penal como tipo sin nombre. Pero, como ocurre con la vida y la libertad, las dificultades aumentan para proteger penalmente la dignidad desde el momento en que se van despenalizando -no discriminalizando- los ataques a la vida y a la libertad; se van atenuando las penas contra los ataques a la dignidad y se introducen de manera deficiente las que protegen la paz.

Scire. 3 : 1 (ene. -jun. 1997) 55-73 
La novedad del flamante Código ha consistido en el intento de sistematizar la defensa de la intimidad y de otros derechos que no se pueden confundir con ella, pero que son sus protectores: la inviolabilidad del domicilio y el secreto de las comunicaciones, delitos que se castigan más gravemente cuando el autor es un funcionario público o una autoridad (art.198), o cuando se conocen por motivos profesionales (art.199). Es, al menos, discutible que el artículo 200 extienda la tutela de la intimidad a las personas jurídicas porque se desvirtúa el concepto estrictamente personal de intimidad. Otra cosa es que las personas jurídicas tengan derecho a que sean reservados ciertos datos como elemento necesario para alcanzar sus fines estatutarios.

En relación con las personas físicas:

- Se castiga a quienes para descubrir secretos o violar la intimidad de otros usan, sin su consentimiento, instrumentos o artificios técnicos de escucha, transmisión o registro del sonido, de la imagen o de otros medios de comunicación (art. 197,1).

- Se castiga a quien, sin autorización, se apropia, utiliza o modifica datos personales o familiares reservados, registrados en soportes informáticos, electrónicos o telemáticos u otro tipo de sistemas de archivo o registro, sean públicos o privados; y se castiga el acceso y alteración no autorizados de dichos datos en perjuicio de su titular o de un tercero (art.197, 2).

- Se castiga con mayor severidad a quien difunde o revela a terceros los datos, hechos o imágenes obtenidos con los medios descritos (art. 197,3); y se agrava también la pena si estos hechos son realizados por los responsables de los archivos o registros informáticos y si se difunden, ceden o revelan (art. 197, 4).

Son agravantes de la pena el que la violación de la tenga por objeto datos personales que revelan la intimidad, ideológía,religión, creencias, salud, origen racial o vida sexual; o que la víctima de la intromisión sea menor o incapaz; o que la agresión se realice con ánimo de lucro (197,5 y 6)

\section{Conclusiones}

En resumen, el derecho a la información a través del ciberespacio encuentra graves dificultades para lograr que sea eficaz. Es cierto que puede ser efectivamente tutelado de lege ferenda por aplicación de los principios jurídico-informativos a la realidadinformática; pero esta protección siempre resultará insegura en la práctica, aunque es muy útil para detectar la anomalía de las situaciones que se plantean. Es necesario un esfuerzo grande para traducir principios a normas positivas legales, convencionales o consuetudinarias que sean ajustadas a la problemática creciente de los nuevos fenómenos comunicativos. La labor de la

Scire. 3 : 1 (ene. -jun. 1997) 55-73 
doctrina y, en su caso, de la jurisprudencia, ha de preparar con finura conceptual el trabajo de los legisladores; y estar siempre alerta ante los cambios mínimos que se produzcan en la realidad técnica.

Scire. 3 : 1 (ene. -jun. 1997) 9-31 